\title{
Caracterização do embasamento da Bacia Paraíba: integração de dados geológicos e aerogeofísicos
}

Gilsijane V. Ramos ${ }^{1}$, David L. Vasconcelos ${ }^{1}$, Francisco H. R. Bezerra ${ }^{1,2}$, David L. de Castro ${ }^{1,2}$, Walter E. de Medeiros ${ }^{1,3}$, Rosangela Correa Maciel ${ }^{3}$

1 - Programa de Pós-Graduação em Geodinâmica e Geofísica - UFRN

2 - Departamento de Geologia - UFRN

3 - Departamento de Geofísica - UFRN

Copyright 2016, SBGf - Sociedade Brasileira de Geofísica

Este texto foi preparado para a apresentação no VII Simpósio Brasileiro de Geofísica, Ouro Preto, 25 a 27 de outubro de 2016. Seu conteúdo foi revisado pelo Comitê Técnico do VII SimBGf, mas não necessariamente representa a opinião da SBGf ou de seus associados. É proibida a reprodução total ou parcial deste material para propósitos comerciais sem prévia autorização da SBG.

\section{Abstract}

This research integrates geophysical and geological data in order to characterize geologically the Paraíba Basin and its basement. The radiometric data were associated with surface geology collaborating with the delimitation of geological contacts. While the magnetic data aided identifying shear zones in crystalline basement and their continuity into the Paraíba Basin, interpreted as faults. The integration of geophysical data with existing geology describes the regional geology and tectonics describes associating this data with existing research.

\section{Introdução}

A utilização de dados geofísicos tem se mostrado fundamental para a caracterização de contatos (gamaespectometria) e estruturas geológicas (magnetometria) do embasamento de bacias sedimentares brasileiras (Andrades-Filho et al., 2014; Jacques et al., 2014). A integração destes dados com a geologia permite diferenciar unidades geológicas (Oliveira e Medeiros, 2014) e identificar a continuidade de estruturas dúcteis do embasamento em bacias sedimentares (Bezerra et al., 2014). Nesse contexto, o uso de métodos geofísicos no mapeamento geológico/estrutural tem se tornado comum em pesquisas de bacias sedimentares no NE do Brasil (p.ex., Andrades Filho et al., 2014; Bezerra et al., 2014; De Castro et al., 2014; Jacques et al., 2014).

O objetivo deste trabalho é a correlação de dados aerogeofísicos e geológicos na caracterização de unidades e estruturas geológicas da Bacia Paraíba e do seu embasamento pré-cambriano. A área pesquisa da está situada na porção centro-leste da Província Borborema e compreende o limite sul da porção emersa da Bacia Paraíba e partes da Zona Transversal e da Sub-província Meridional (Figs. 1 e 2).

A Bacia Paraíba é uma bacia de margem passiva formada nos estágios finais da abertura do Oceano Atlântico
(Matos, 1992). Esta se encontra na margem continental brasileira entre a Zona de Cisalhamento Pernambuco (ZCPE) e o Alto de Touros (Lima Filho, 1998; Bezerra et al., 2014). Contudo, algumas pesquisas, apontam que a Bacia Paraíba compreende o trecho entre a ZCPE e o Alto de Mamanguape (Barbosa e Lima Filho, 2006; Correia Filho et al., 2015), sendo o segmento entre os altos de Mamanguape e Touros, interpretado como Plataforma de Natal (Barbosa e Lima Filho, 2006).

O embasamento da Bacia Paraíba é composto por rochas pré-cambrianas da Província Borborema (Andrades Filho et al., 2014; Correia Filho et al., 2015), a qual é compartimentada em subprovíncias: Setentrional, Transversal e Meridional (Delgado et al., 2003) (Figura 1). Na área de estudo, afloram rochas das Subprovíncias Meridional (Terreno Pernambuco-Alagoas) e Zona Transversal (Terrenos Alto Moxotó e Rio Capibaribe). O Terreno Pernambuco-Alagoas encontra-se ao sul da ZCPE, o qual é formado em grande parte pelos complexos Cabrobó e Belém do São Francisco. Entre a ZCPE e a Zona de Cisalhamento Cruzeiro do Nordeste (ZCCN) encontra-se o Terreno Rio Capibaribe. Este terreno é composto por rochas dos complexos metaplutônicos Pão de Açúcar e Salgadinho, Complexo Surubim-Caroalina e pela sequência metavulcanossedimentadar do Complexo Vertentes. Por fim, ao norte da ZCCN encontra-se o Terreno Alto Moxotó, o qual possui predominância de rochas metassedimentares do Complexo Sertânia e os complexos metaplutônicos Floresta e Cabaceiras.

A Bacia Paraíba, segundo a mais recente carta estratigráfica (Correia Filho et al., 2015), possui sete unidades litoestratigráficas. Na porção basal, está a Formação Beberibe, composta por arenitos flúvio-lacustre de idade Coniaciana-Campaniana (Beurlen, 1967). Sobreposta a esta, está a Formação Itamaracá, caracterizada por arenitos calcíferos, margas e calcários de idade Campaniana-Maastrichtiana (Kegel, 1955). Acima desta, encontram-se os carbonatos depositados em ambiente de plataforma rasa das formações Gramame, Maria Farinha e Tambaba de idade Maastrichtiana-Ypresiana (Correia Filho et al., 2015; Beurlen, 1967). Por fim, na porção superior desta bacia, encontra-se os sedimentos siliciclásticos da Formação Barreiras e Depósitos PósBarreiras de idade Miocênica e Pleistocênica-Holocênica, respectivamente (Rossetti et al., 2011). 


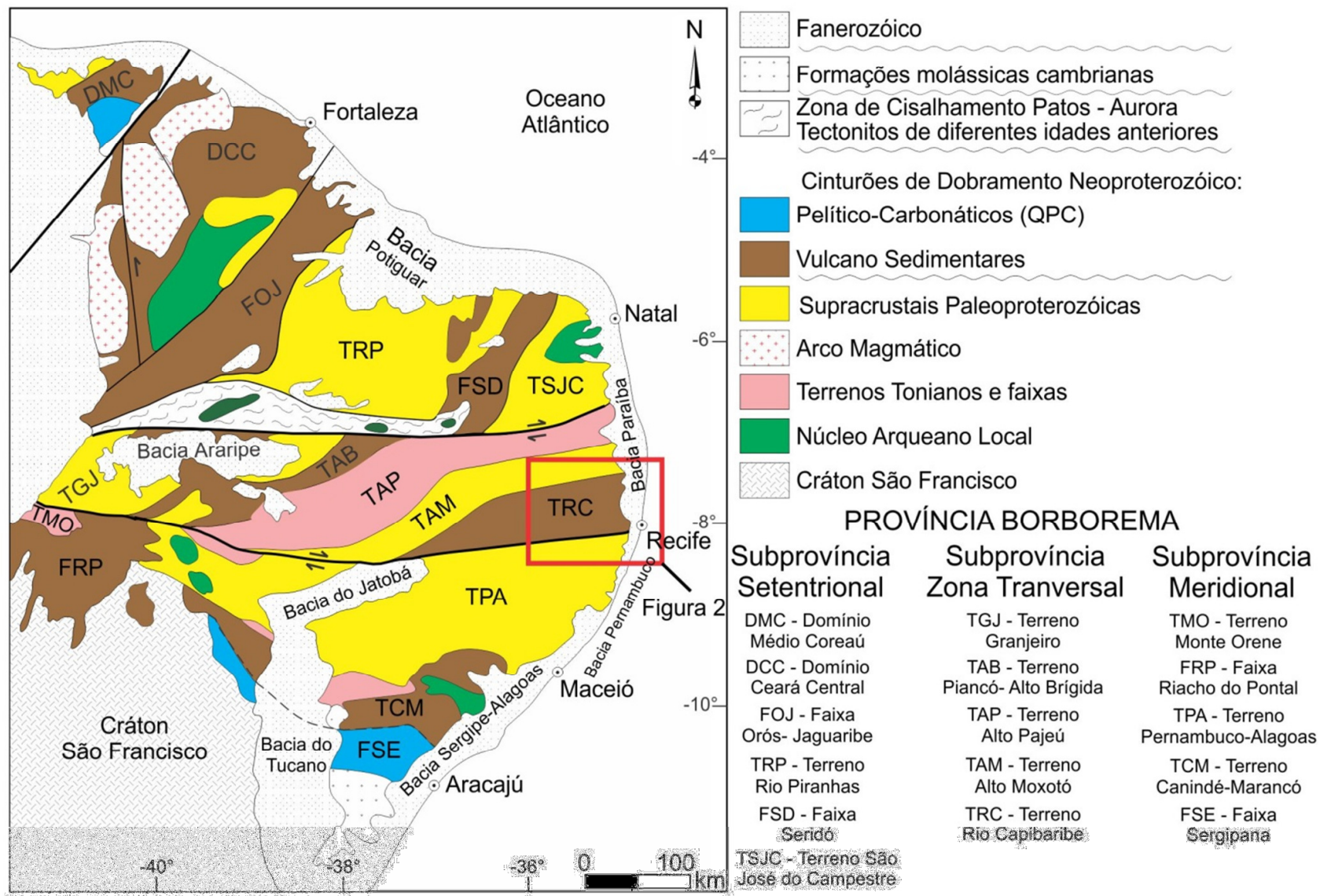

Figura 1 - Mapa geológico da Província Borborema com a localização da área de estudo (Polígono vermelho). Separação de Domínios e Terrenos segundo Santos e Medeiros (1999) e Santos (2000). Adaptado de Oliveira (2008).

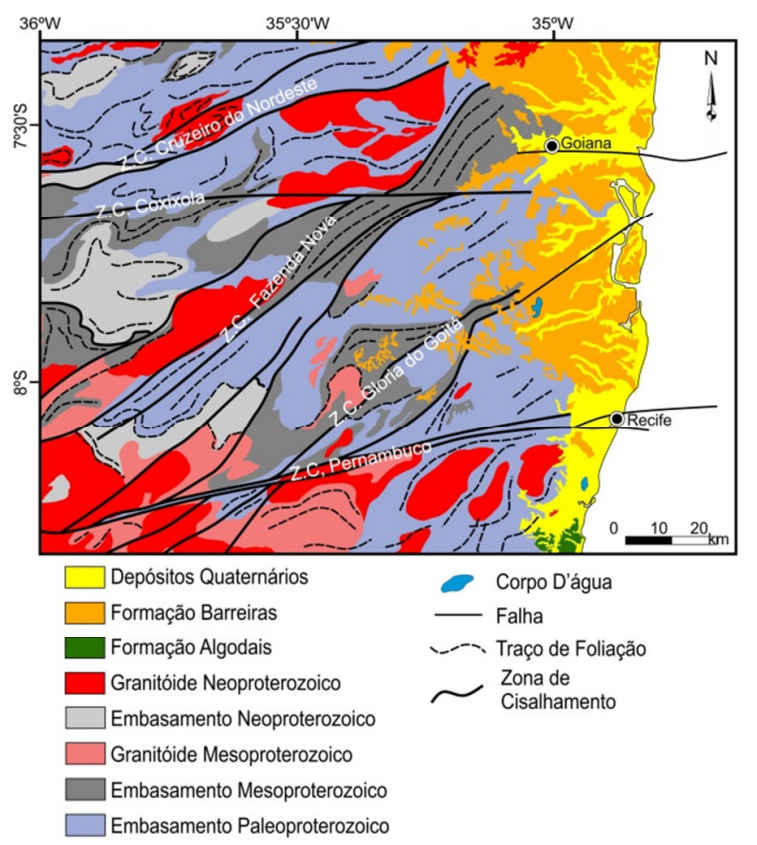

Figura 2 - Mapa geológico da borda sul da Bacia Paraíba emersa e do embasamento cristalino adjacente.

\section{Metodologia}

Nós compilamos os dados geológicos/estruturais das Folhas Natal e Recife (Angelim et al., 2004; Angelim e Wanderley, 2004) e as principais estruturas geológicas (Bezerra et al., 2014) focando principalmente os contatos e as zonas de cisalhamento. Com isso, confeccionamos um mapa geológico e estrutural da área de pesquisa (Fig. 2). Com objetivo de facilitar a interpretação, nós agrupamos as unidades quaternárias em uma única classe: Depósitos Quaternários.

Posteriormente, foram usados dados aerogeofísicos do Projeto Aerogeofísico Borda Leste do Planalto da Borborema (LASA \& PROSPECTORS, 2008) cedido pelo Serviço Geológico do Brasil (CPRM). O projeto levantou perfis magnetométricos e gamaespectrométricos, com linhas de voo e controle espaçadas de $500 \mathrm{~m}$ e $5.000 \mathrm{~m}$, orientadas nas direções N-S e E-W, respectivamente, e com altura de voo fixada em $100 \mathrm{~m}$ sobre o terreno. Os dados fornecidos já estavam micronivelados e corrigidos pelo IGRF (International Geomagnetic Reference Field). Este levantamento usou gamaespectômetros com cristais de iodeto de sódio ( $\mathrm{Nal}$ ), o qual detectou fotopicos de potássio, equivalente tório e equivalente urânio, com as medidas sendo efetuadas a cada 0,1 segundo e magne- 
tômetros com sensor de vapor de césio, montado na cauda na aeronave "stinger" e as medidas sendo efetuadas a cada 0,1 segundo. Os dados foram processados com o software Oasis Montaj 8.2 da Geosoft.

Os dados aerogamaespectométricos foram interpolados usando o método da mínima curvatura com células de espaçamento de $250 \mathrm{~m}$ (metade do espaçamento entre as linhas de voos), gerando os mapas dos canais: eU, eTh, e Kperc. Um mapa ternário (RGB) foi confeccionado através dos canais Kperc, eTh e eU. A Figura 3 resume as etapas de processamento dos dados aerogamaespectométricos.

\section{Processamento dos dados gamaespectométricos}

Interpolação usando mínima curvatura (célula: $250 \mathrm{~m}$ )

Mapas dos canais (eU, eTh, Kperc e CT)

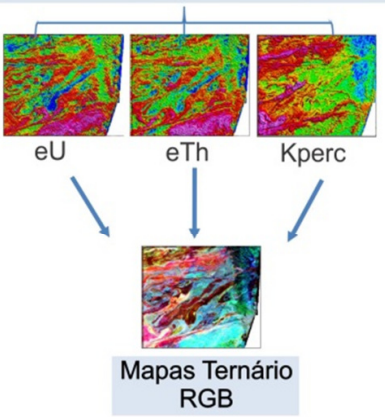

Figura 3: Etapas do processamento dos dados gamaespectométricos.

Os dados aeromagnéticos foram interpolados utilizando $o$ método Bidirecional, gerando uma malha regular do Campo Magnético Anômalo (CMA), com células de 250 $\mathrm{m}$ (metade do espaçamento entre as linhas de voos). Em seguida geramos o mapa do Campo Magnético Anômalo Reduzido ao Polo (RTP), com inclinação de $-25^{\circ}$, declinação de $-22^{\circ}$ e pseudo-declinação de $60^{\circ}$. A Figura 4 resume as etapas de processamento dos dados aeromagnéticos.

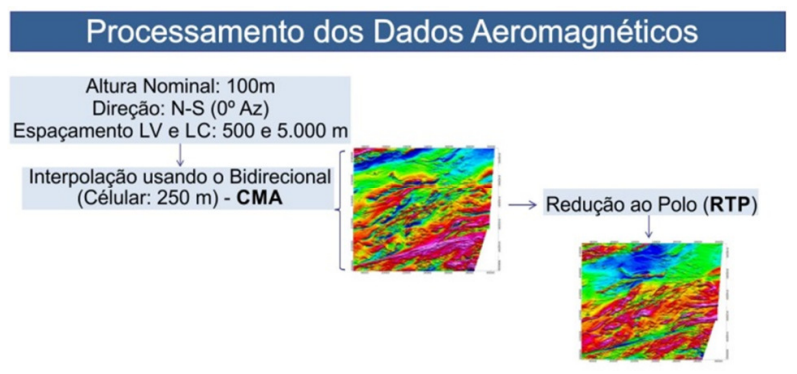

Figura 4: Etapas do processamento dos dados magnéticos.

\section{Resultados}

As investigações foram concentradas na interpretação de contatos e estruturas geológicas entre os diferentes domínios tectônicos. Inicialmente, nós sobrepomos o mapa geológico (Fig. 2) sobre o mapa ternário RGB (Fig. 5).

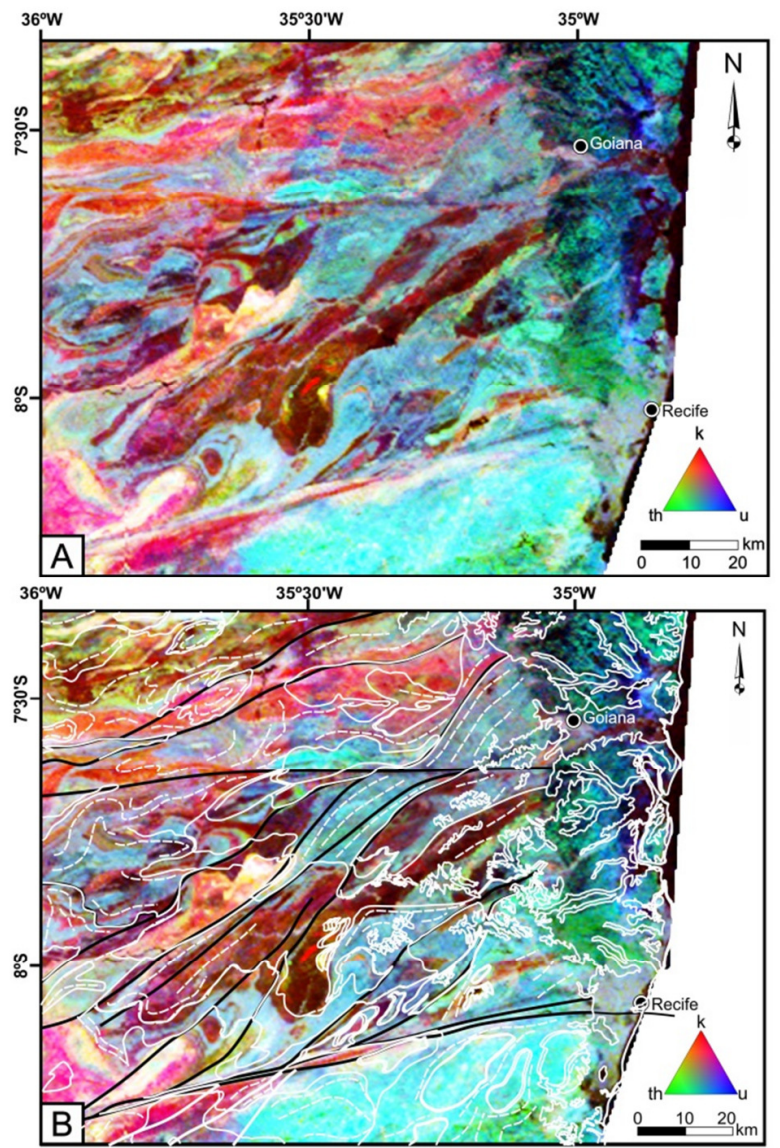

Figura 5 - (A) Composição radiométrica ternária $R G B$. (B) Composição radiométrica ternária $R G B$ com sobreposição de contatos e estruturas geológicas.

O mapa ternário (Figura 5) mostra pelas tonalidades azulada e avermelhada que as rochas do embasamento cristalino estão correlacionadas com valores relativamente mais altos de $\mathrm{U}$ e $\mathrm{K}$, respectivamente. A tonalidade azulada está associada à presença de ortognaisses tonalíticos a graníticos do Complexo Salgadinho, metanortositos e metagabros do Complexo Passira e a ortognaisses tonalíticos a granodioríticos e migmatitos do Complexo Belém do São Francisco. A tonalidade avermelhada está correlacionada a metassedimentos do Complexo Sertânia, paragnaisses com intercalações de metavulcânicas máficas e rochas calcissilicáticas do Complexo Vertentes, metassedimentos do Complexo Surubim-Caroalina, granitos e granodioritos da Suíte Itaporanga e sienitos, mozonitos e monzogranitos da Suíte Terra Nova. Estas suítes possuem formas semicirculares correlacionas às intrusões graníticas da orogenia Brasiliana (Oliveira e Medeiros, 2014).

Os metassedimentos descritos acima se mostram enriquecidos em potássio. Contudo, exibe uma concentração de Th evidenciada pela tonalidade esverdeada menos expressiva do que a concentração de K. Uma alta concentração de tório pode ser visualizada no extremo noroeste da área de estudo. Esta é caracterizada pelas tonalidades esverdeada a avermelhada. Isso decorre devido à 
composição de ortognaisses tonalíticos a granodioríticos do Complexo Cabaceiras, ortognaisses e migmatitos do Complexo Serra de Jabitacá e leuco-ortognaisses trondhjemíticos a granodioríticos do Complexo Sumé.

$\mathrm{Na}$ região da Bacia Paraíba, observamos tonalidades predominantemente azuladas e esverdeadas, evidenciando que as unidades sedimentares estão correlacionadas com o enriquecimento em Th e U. A tonalidade esverdeada está associada a rochas da Formação Barreiras com composição enriquecida em Th. A tonalidade azulada expressa uma correlação com os sedimentos quaternários com composição enriquecida em U.

Posteriormente, nós interpretamos os dados magnéticos subdividindo a área em três domínios (Fig. 6). Os lineamentos magnéticos interpretados nesses domínios caracterizam zonas de cisalhamento ocorrentes no embasamento cristalino, e com isso podemos observar que na região da bacia sedimentar, a continuidade desses lineamentos é interpretada como reativações frágeis (falhas) (Fig. 6).

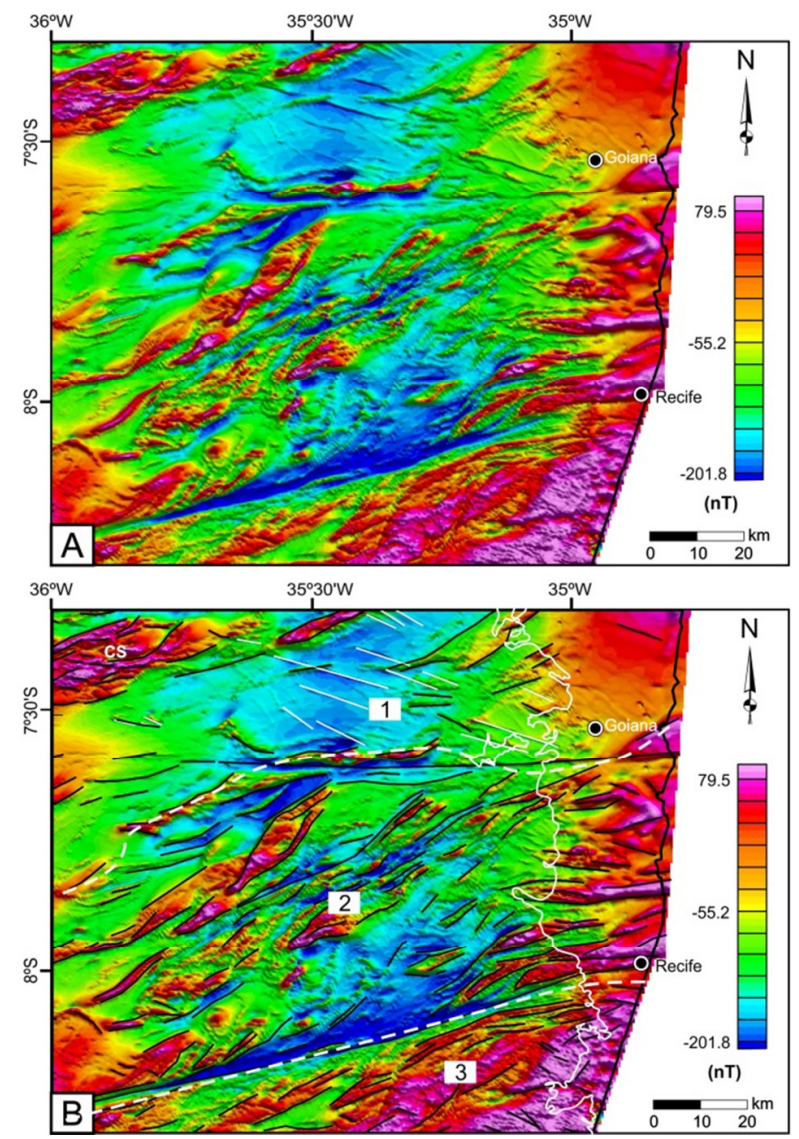

Figura 5 - (A) Mapa de anomalias reduzidas ao polo (RTP). (B) Interpretação dos principais lineamentos magnéticos. Traços contínuos pretos: zonas de cisalhamento; Traços contínuos brancos: diques; Traços pontilhados brancos: limite dos domínios magnéticos.

O Domínio 1 está localizado ao norte da Zona de CisaIhamento Coxixola (ZCC) (Fig. 6A). É caracterizado por apresentar as anomalias magnéticas de mais baixas amplitudes. Podemos observar uma significante anomalia positiva a noroeste da área, devido à presença de leucoortognaisses com formações ferríferas do Complexo Sumé (CS).Também ocorre a presença de diques máficos ricos em sílica (Almeida e Hollanda, 2009) de direção NW-SE. Este domínio pode ser correlacionado ao Terreno Alto Moxotó.

O Domínio 2 está limitado pela ZCC ao norte e pela ZCPE ao sul. Este domínio é caracterizado por possuir anomalias magnéticas positivas e negativas de altas amplitudes e exibir dois trends principais de lineamentos magnéticos com orientação NE-SW, na porção ocidental e E-W, na porção oriental desse domínio (Fig. 6). Podemos observar anomalias estreitas, alongadas e às vezes vergadas em forma de sigmoides ou semicirculares. Este domínio pode ser correlacionado ao Terreno Rio Capibaribe.

O Domínio 3 está localizado a sul da ZCPE e exibe anomalias magnéticas de amplitude que variam de medianas a elevadas, com lineamentos magnéticos de direção NESW (Fig. 6). Podemos observar uma expressiva anomalia positiva a sudeste da área, devido à presença de ortognaisses do Complexo Belém do São Francisco e intrusões graníticas da Suíte Itaporanga. Este domínio pode ser correlacionado ao Terreno PernambucoAlagoas.

Podem-se observar na região da bacia sedimentar assinaturas magnéticas de mais altas amplitudes, principalmente mais a sul da região, sendo estes correlacionados a granitoides do neoproterozoico. E dentro desta bacia, também se observa anomalias mais alongadas, as quais estas estão relacionadas à continuidade de zonas de cisalhamento sotopostas a Bacia Paraíba.

\section{Conclusões}

Os dados radiométricos, pela sua característica de investigação rasa, possuem associação com a geologia superficial, colaborando com a delimitação de contatos geológicos, tais como a Formação Barreiras e os Depósitos Quaternários, e a delimitação de intrusões graníticas do embasamento cristalino.

A interpretação dos dados aeromagnéticos possibilitou uma divisão de três domínios magnéticos correlacionados com terrenos geológicos da Província Borborema. Os lineamentos magnéticos interpretados auxiliaram na identificação de zonas de cisalhamento no embasamento cristalino, sendo a sua continuidade na Bacia Paraíba, interpretada como falhas.

\section{Referências}

Almeida, V. V. e Hollanda, M. H. B. M. 2009. Petrografia, química mineral e litoquímica de diques máficos cambrianos do extremo oriental do estado da Paraíba. Revista Brasileira de Geociências, v. 39(3): 580 - 598.

Andrades Filho, C.O.; Rosseti, D.F.; Bezerra, F.H.R.; Medeiros, W.E.; Valeriano, M.M; Cremon, E.H.; Oliveira, R.G. 2014. Mapping Neogene and Quaternary sedimentary deposits in northeastern Brazil by integrating geophysics, remote sensing and geological field data. 
Journal of South American Earth Sciences, v.56, p.316327.

Angelim L.A.A, Vasconcelos A.M, Gomes J.R.C, Wanderley A.A, Forgiarini L.L e Medeiros M.F. 2004. Folha SB24-Jaguaribe. Carta Geológica do Brasil ao Milionésimo, SIG. Programa Geologia do Brasil. CPRM, Brasília. CDROM.

Angelim, L. A. A. e Wanderley, A. A. 2004. Folha SC.25Recife. Carta Geológica do Brasil ao Milionésimo, SIG. Programa Geologia do Brasil. CPRM, Brasília. CD-ROM.

Barbosa, J.A e Lima Filho, M. F. 2006. Aspectos estruturais e estratigráficos da faixa costeira recife-natal observados através de dados de poços. Boletim de Geociências da Petrobrás, (14) 2: 287-305.

Beurlen, K. 1967. Estratigrafia da faixa sedimentar costeira Recife-João Pessoa. Boletim Geológico, São Paulo, 16(1), 43-53.

Bezerra, F.H.R.; Rosseti, D.F.; Oliveira, R.G.; Medeiros, W.E.; Neves, E.B.; Balsamo, F.; Nogueira, F.C.C.; Dantas, E.L.; Andrades Filho, C.; Góes, A.M. 2014. Neotectonic reactivation of shear zones and implications for faulting style and geometry in the continental margin of NE Brazil. Tectonophysics (Amsterdam), 614, 78-90.

Correia Filho, O. J., Alencar, M. L., Barbosa, J. A. e Neumann, V. H. 2015. Proposta de formalização da Formação Tambaba, eoceno da Bacia Paraíba, NE do Brasil. Estudos Geológicos, v. 25(2).

De Castro, D.L.; Fuck, R.A.; Phillips, J.D.; Vidotti, R.M.; Bezerra, F.H.R.; Dantas, E.L. Crustal structure beneath the Paleozoic Parnaíba Basin revealed by airborne gravity and magnetic data, Brazil. Tectonophysics, v. 614, p. 128-145, 2014.

Delgado I.M., Souza J.D., Silva L.C., Silveira Filho N.C., Santos R.A., Pedreira A.J., Guimarães J,T, Angelim L.A.A., Vasconcelos A.M., Gomes I.P., Lacerda Filho J.V., Valente C.R., Perrotta M.P., Heineck C.A., 2003. Geotectônica do Escudo Atlântico. In: L.A. Bizzi, C. Schobbenhaus, R.M. Vidotti, J.H. Gonçalves. eds., 2003. Geologia, tectônica e recursos minerais do Brasil. Brasília, CPRM. 227-334.

Jacques, P.D.; Machado, R.; Oliveira, R. G.; Ferreira, F.J.F.; Castro, L.G.; Nummer, A.R. 2014. Correlation of lineaments (magnetic and topographic) and Phanerozoic brittle structures with Precambrian shear zones from the basement of the Paraná Basin, Santa Catarina State, Brazil. Brazilian Journal of Geology, v. 44, p. 39-64.

Kegel, W. 1955. Geologia do fosfato de Pernambuco. Boletim da Divisão de Geologia Mineral, Rio de Janeiro, DNPM, 157, 54.

Lasa \& Prospectors. 2008. Projeto Aerogeofísico Borda Leste do Planalto da Borborema. MME/CPRM, Relatório Final, Rio de Janeiro, p. 401.

Lima Filho, M.F. Análise Estrutural e Estratigráfica da Bacia Pernambuco. São Paulo, 1998, 139 p. Tese (Doutorado) - Instituto de Geociências, Universidade de São Paulo.

Oliveira, R. G. e Medeiros, V. C. 2014. Aplicação de Dados Aerogamaespectrométricos e Aeromagnetométricos no Mapeamento da Faixa Dobrada Seridó (RN/PB) e de seu Embasamento. Serviço Geológico do Brasil - CPRM. Boletim SBGF - 88: 20-23.

Rossetti, D.F.; Bezerra, F.H.; Góes, A.M; Valeriano, M.M; Andrades Filho, C.O.; Mittani, J.C.R.; Tatumi, S.H.; BritoNeves, B.B. 2011. Sediment deformation in Miocene and post-Miocene strata, Northeastern Brazil: evidence for paleoseismicity in a passive margin. Sedimentary Geology, v. 235, p. 172-187.

Santos, E. J.; Medeiros, V. 1999. Constraints from granitic plutonism on proterozoic crustal growth of the Zona Transversal domain, Província Borborema, NE Brazil. Revista Brasileira de Geociências, v. 29: 73-84.

Santos, E.J; Ferreira, C.A. Geologia e recursos minerais do Estado da Paraíba. 2002. Serviço Geológico do Brasil - CPRM, Brasília, p. 1-110. 